\title{
HUBUNGAN ANTARA PRESTASI BELAJAR KIMIA DENGAN KETERAMPILAN KOMUNIKASI LISAN BERDASARKAN PERSEPSI SISWA
}

\author{
Lukmanul Hakim $^{1}$, Yayuk Andayani ${ }^{2 *}$, Jeckson Siahaan ${ }^{3}$ \\ ${ }^{123}$ Program Studi Pendidikan Kimia FKIP Universitas Mataram. Jalan Majapahit No. 62 Mataram, \\ NTB 83112, Indonesia. \\ *Coressponding Author, Email: yayukmtr@gmail.com
}

Received: 17 Mei 2021

Accepted: 30 November 2021

Publish: 30 November 2021

doi: 10.29303/cep.v4i3.2657

\begin{abstract}
Abstrak
Penelitian ini bertujuan untuk mengetahui hubungan antara prestasi belajar kimia dengan keterampilan komunikasi lisan berdasarkan persepsi siswa. Penelitian kuantitatif ex-post facto melibatkan sebanyak 231 siswa sebagai sampel yang ditentukan menggunakan proportionate stratified random sampling. Data keterampilan komunikasi lisan dikumpulkan menggunakan angket dan data prestasi belajar kimia siswa dari dokumen guru. Teknik analisis korelasi Pearson Product Moment digunakan untuk uji hipotesis dan analisis deskriptif untuk menjelaskan tingkat ketercapaian prestasi maupun komunikasi lisan siswa. Hasil uji hipotesis menunjukkan adanya hubungan positif dan signifikan $\left(\mathrm{t}_{\text {hitung }}=\right.$ $12057,742>t_{\text {tabel }}=3,89$ ) antara prestasi belajar kimia dan keterampilan komunikasi lisan siswa kelas XI MIA di SMAN Mataram dan Lombok Barat Tahun Ajaran 2020/2021, namun hubungannya sangat rendah $\left(r_{x y}=0,10\right)$. Hasil analisis statistik deskriptif menunjukkan bahwa kategori ketercapaian rata-rata nilai untuk prestasi belajar kimia dan keterampilan komunikasi lisan siswa kelas XI MIA di SMAN Mataram dan Lombok Barat Tahun Ajaran 2020/2021 secara keseluruhan termasuk kategori tinggi.
\end{abstract}

Kata Kunci : Prestasi Belajar Kimia, Keterampilan Komunikasi Lisan, Persepsi.

\section{Relationship Between Chemistry Learning Achievement and Oral Communication Skill Based on Student's Perception}

\begin{abstract}
This study aims to find out the relationship between chemistry learning achievements and oral communication skill based on students' perception. The quantitative research ex-post facto involving as many as 231 students as a sample determined using proportionate stratified random sampling. Oral communication skill data are collected by using questionnaires and student chemistry learning achievement data from teacher documents. Correlation analysis techniques of Pearson Product Moment are utilized for hypothesis testing and descriptive analysis to explain the level of achievement and oral communication of students. Hypothetical test results indicate a positive and significant relationship $\left(t_{\text {count }}=12057,742>t_{\text {table }}=3,89\right)$ between the achievement of learning chemistry and oral communication skill of grade XI Science students at Senior High School (SMAN) of Mataram and West Lombok School Year 2020/2021, but the relationship is very low $\left(r_{x y}=0,10\right)$. The results of descriptive statistic analysis indicates the category of the average achievement of grades for chemistry learning achievement and oral communication skill of grade XI Science students at Public High School of Mataram and West Lombok School Year 2020/202 las a whole is categorized as a high category.
\end{abstract}

Keywords : Student Achievement, Oral Communication Skill, Perception.

\section{PENDAHULUAN}

Pembelajaran merupakan suatu proses yang bersifat kompleks. Pembelajaran bukan hanya diartikan sebagai sebuah proses yang dilakukan siswa untuk memperoleh ilmu dari seorang guru, tetapi proses pembelajaran juga memiliki aspek yang harus dicapai untuk dapat dikatakan proses tersebut berjalan dengan baik. Sanjaya (2008) menyatakan bahwa pembelajaran merupakan suatu sistem yang kompleks yang keberhasilannya dapat dilihat dari dua aspek, 


\section{Chemistry Education Practice, 4 (3), 2021 - 238}

Hakim, Andayani, Siahaan

yakni aspek proses dan aspek produk. Kedua sisi ini sama pentingnya, karena dalam pembelajaran harus memperhatikan kedua aspek tersebut untuk dapat mencapai tujuan sebenarnya dari pembelajaran itu sendiri.

Menurut Yusefni (2015) komunikasi lisan adalah penyampaian informasi yang dilakukan melalui ucapan kata-kata atau kalimat. Dalam pembelajaran sains kemampuan berkomunikasi secara lisan biasanya terjadi pada saat diskusi karena terjadi proses interaksi dalam mengerjakan soal, setiap anggota kelompok akan berinteraksi secara langsung dalam kelompok. Interaksi ini bermaksud agar setiap anggota kelompok dapat berhubungan saling membantu (Yusefni, 2015). Menurut Aulia (2018) aspek dalam keterampilan komunikasi lisan dalam pembelajaran meliputi : 1) mampu menyampaikan pemahaman secara lisan, 2) menggunakan tata bahasa yang baik, 3) mampu menghargai lawan bicara, 4) mampu memberikan pendapat, 5) mampu memberikan pertanyaan yang relevan, dan 6) mampu memberikan pemahaman yang jelas dan mudah dimengerti. Siswa yang tidak melakukan komunikasi dalam belajar cenderung menunjukkan prestasi belajarnya rendah, sebaliknya siswa yang memiliki komunikasi dalam belajar cenderung menunjukkan prestasi belajar yang tinggi. Jadi tinggi rendahnya prestasi belajar dipengaruhi oleh keterampilan komunikasi yang dimiliki siswa dalam proses pembelajaran (Mulyasa, 2005).

Berdasarkan hasil observasi di SMAN 4 Mataram, SMAN 7 Mataram, SMAN 1 dan SMAN 2 Narmada diperoleh informasi bahwa kemampuan berkomunikasi siswa masih kurang. Demikian juga dengan prestasi siswamenunjukkan nilai rata-rata hasil belajar siswa masih ada yang berada dibawah Kriteria Ketuntasan Minimal (KKM) yaitu nilai 75 (Tabel 1).

Tabel 1. Data Nilai Rata-rata UAS Tahun Ajaran 2020/2021

\begin{tabular}{ccccc}
\hline \multicolumn{5}{c}{ SMAN 4 Mataram } \\
\hline No & Kelas & $\begin{array}{c}\text { Jumlah } \\
\text { Siswa }\end{array}$ & $\begin{array}{c}\text { KKM } \\
\text { (Ketuntasa } \\
\text { n Kerja } \\
\text { Minimal) }\end{array}$ & $\begin{array}{c}\text { Nilai } \\
\text { rata- } \\
\text { rata }\end{array}$ \\
\hline 1 & XI MIA 1 & 36 & & 67,97 \\
2 & XI MIA 2 & 35 & 75 & 63,71 \\
3 & XI MIA 3 & 36 & & 60,05 \\
4 & XI MIA 4 & 34 & 49,76 \\
\hline \multicolumn{5}{c}{ SMAN 7 Mataram } \\
\hline 1 & XI MIA 1 & 36 & 81,63 \\
2 & XI MIA 2 & 35 & 75 & 82,08 \\
3 & XI MIA 3 & 36 & & 81,36 \\
4 & XI MIA 4 & 35 & & 82,62 \\
5. & XI MIA 5 & 34 &
\end{tabular}

\begin{tabular}{|c|c|c|c|c|}
\hline \multicolumn{5}{|c|}{ SMAN 1 Narmada } \\
\hline 1 & XI MIA 1 & 35 & \multirow{5}{*}{75} & 80,68 \\
\hline 2 & XI MIA 2 & 33 & & 82,78 \\
\hline 3 & XI MIA 3 & 35 & & 79,42 \\
\hline 4 & XI MIA 4 & 35 & & 76,57 \\
\hline 5. & XI MIA 5 & 36 & & 80,52 \\
\hline \multicolumn{5}{|c|}{ SMAN 2 Narmada } \\
\hline 1 & XI MIA 1 & 27 & \multirow{2}{*}{75} & 57,37 \\
\hline 2 & XI MIA 2 & 28 & & 74,85 \\
\hline
\end{tabular}

(Sumber: Arsip Guru SMAN 4 Mataram, SMAN 7 Mataram, SMAN 1 Narmada dan SMAN 2 Narmada

Menurut Rubiman (2012) prestasi belajar siswa diukur melalui penilaian ranah kognitif, ranah afektif dan ranah psikomotorik. Penilaian kognitif meliputi kemampuan siswa dalam memahami konsep-konsep atau teori-teori atau hukum-hukum pada mata pelajaran kimia. Penilaian afektif digunakan untuk mengukur sikap dan minat siswa terhadap mata pelajaran kimia. Sedangkan penilaian psikomotorik digunakan untuk mengukur penampilan atau kinerja (performance) yang telah dikuasai.

Hasil ini sesuai dengan hasil wawancara guru bahwa prestasi belajar siswa juga dipengaruhi oleh komunikasi lisan antara guru dengan siswa. Guru harus memiliki komunikasi yang baik dan melihat karakteristik siswa serta dapat mendekatkan diri kepada siswa agar siswa tersebut bisa belajar kimia dengan mudah mengerti, nyaman dan maksimal. Disisi lain, siswa dituntut mampu untuk mengkomunikasikan ilmu pengetahuan yang sudah didapatkan dan mampu menyampaikannya melalui interaksi dengan guru maupun siswa lainnya.

Partisipasi siswa yang aktif dalam pembicaraan kelas dapat dihubungkan dengan prestasi siswa yang lebih baik. Hal ini dikarenakan adanya perubahan pada setiap prestasi siswa yang berkaitan dengan kualitas dialog kelas. Kemudian siswa yang tidak memiliki komunikasi dalam belajar cenderung menunjukkan prestasi belajarnya rendah, sebaliknya siswa yang memiliki komunikasi dalam belajar cenderung menunjukkan prestasi belajar yang tinggi. Jadi tinggi rendahnya prestasi belajar dipengaruhi oleh keterampilan komunikasi yang dimiliki siswa dalam proses pembelajaran.

Hasil penelitian Fatmadewi (2019) menunjukkan bahwa dengan menerapkan model pembelajaran yang efektif dapat memberikan pengaruh positif terhadap keterampilan komunikasi dan prestasi siswa di bidang kimia. Menurut Iftitah (2019) adanya tanya jawab dalam diskusi juga dapat membawa pengaruh 


\section{Chemistry Education Practice, 4 (3), 2021 - 239}

Hakim, Andayani, Siahaan

positif terhadap kemampuan komunikasi lisan siswa. Kemampuan komunikasi lisan yang terlatih dengan baik akan mempermudah siswa dalam menyampaikan informasi - informasi yang didapat sehingga akan mempermudah siswa lain untuk memahami apa yang disampaikan pada saat melakukan diskusi.

Berdasarkan uraian di atas, diketahui bahwa prestasi belajar kimia dan komunikasi lisan penting dalam pembelajaran, namun kajian terhadap pengaruh-pengaruh prestasi dengan komunikasi lisan khususnya pada siswa SMA di Mataram belum banyak dilaporkan. Tujuan dari penelitian ini adalah untuk mengetahui hubungan antara prestasi belajar kimia dengan keterampilan komunikasi lisan berdasarkan persepsi siswa kelas XI MIA di SMAN Mataram dan Lombok Barat Tahun Ajaran 2020/2021.

\section{METODE}

Penelitian ini dilaksanakan di 4 sekolah yaitu SMAN 4 Mataram, SMAN 7 Mataram, SMAN 1 dan SMAN 2 Narmada pada semester I (Ganjil) Tahun Ajaran 2020/2021. Tahapan penelitian meliputi tahap perencanaan dengan kegiatan penyusunan proposal, administrasi izin penelitian, serta menyusun instrumen penelitian, tahap pengumpulan data, dan tahap pengolahan data serta analisis data.

Jenis penelitian kuantitatif ex-post facto digunakan karena peneliti tidak memanipulasi atau memberi perlakuan (Hamdi, 2014) Penelitan expost facto bertujuan untuk menyelidiki apakah kondisi yang sudah ada dapat menyebabkan perbedaan lanjutan dalam kelompok subjek (Sugiyono, 2016). Rancangan penelitian menggunakan korelasional,bertujuan untuk mengetahui apakah ada hubungan dan tingkat hubungan antara dua variabel atau lebih (Arikunto, 2016)

Variabel penelitian yang digunakan yaitu prestasi belajar kimia dan keterampilan komunikasi lisan siswa. Populasi berjumlah 546 siswa dan sampel ditentukan dengan teknik proportionate stratified random sampling (Arikunto,2013) menggunakan rumus Slovin pada taraf kesalahan 5\% (Ridwan,2005), sehingga diperoleh 231 siswa.

Instrumen untuk mengumpulkan data keterampilan komunikasi lisan berdasarkan persepsi siswa menggunakan angket (questionnaire) sedangkan prestasi belajar kimia menggunakan data nilai Ujian Akhir Semester (UAS) siswa yang didapat dari dokumen guru masing-masing sekolah. Instrumen telah diuji validitas menggunakan korelasi product moment Pearson (Sugiyono, 2016) diperoleh 22 butir soal dinyatakan valid dari 24 butir soal yang diuji. Hasil uji reliabilitas diperoleh nilai Cronbach Alpha, sebesar 0,834 yang menyatakan tingkat realibilitas soal tinggi. Uji prasyarat menggunakan uji normalitas dan linearitas sementara uji hipotesis menggunakan analisis regresi sederhana dan korelasi product moment Pearson (Sugiyono, 2016).

\section{HASIL DAN PEMBAHASAN}

Data keterampilan komunikasi lisan siswa dan prestasi belajar yang telah diperoleh, dianalisis secara deskriptif dalam bentuk nilai rata-rata frekuensi yang disajikan dalam Tabel 2 dan Tabel 3.

Tabel 2.Keterampilan Komunikasi Lisan Siswa

\begin{tabular}{cccc}
\hline Strata & $\begin{array}{c}\text { Jumlah } \\
\text { Sampel }\end{array}$ & Rata-rata & Kategori \\
\hline Mataram & 134 & 72 & Tinggi \\
Narmada & 97 & 73 & Tinggi \\
\hline Jumlah & 231 & 145 & \\
\hline
\end{tabular}

Tabel 3. Prestasi Belajar Kimia Siswa

\begin{tabular}{cccc}
\hline Strata & $\begin{array}{c}\text { Jumlah } \\
\text { Sampel }\end{array}$ & $\begin{array}{c}\text { Rata- } \\
\text { rata }\end{array}$ & Kategori \\
\hline Mataram & 134 & 74 & Tinggi \\
Narmada & 97 & 79 & Tinggi \\
\hline Jumlah & 231 & 153 & \\
\hline
\end{tabular}

Hasil analisis data untuk keterampilan komunikasi lisan (X) diperoleh chi kuadrat hitung $=13,127$ dan chi kuadrat tabel $=15,507$ dengan derajat kebebasan $(\mathrm{dk})=8$ dan taraf signifikan $(\alpha)=0,05$, maka chi kuadrat hitung <chi kuadrat tabel maka data berdistribusi normal. Sedangkan untuk prestasi belajar kimia (Y) diperoleh chi kuadrat hitung $=12,758$ dan chi kuadrat tabel $=15,507$ dengan derajat kebebasan $(\mathrm{dk})=8$ dan taraf signifikan $(\alpha)=$ 0,05 , diperoleh chi kuadrat hitung < chi kuadrat tabel maka data berdistribusi normal.

Hasil uji linieritas variabel keterampilan komunikasi lisan (X) dengan prestasi belajar kimia $(\mathrm{Y})$ menunjukkan koefisien $\mathrm{F}_{\text {hitung }}$ lebih kecil dari $\mathrm{F}_{\text {tabel }}(0,95<1,52)$, maka dapat disimpulkan bahwa keterampilan komunikasi lisan mempunyai hubungan linier dengan prestasi belajar kimia. Hubungan antara keterampilan komunikasi lisan dengan prestasi belajar adalah bentuk hubungan positif dengan tingkat hubungan yang sangat rendah. Dari hasil uji koefisien determinasi diketahui bahwa kontribusi keterampilan komunikasi lisan terhadap prestasi belajar kimia hanya $1 \%$.

Hasil analisis uji $\mathrm{t}$ diperoleh nilai $\mathrm{t}_{\text {hitung }}$ sebesar 12057,742, sedangkan $t_{\text {tabel }}$ dengan derajat kebebasan $(\mathrm{dk})=229$ untuk taraf 


\section{Chemistry Education Practice, 4 (3), 2021 - 240}

Hakim, Andayani, Siahaan

signifikan $(\alpha)=0,05$ diperoleh nilai $t_{\text {tabel }}$ sebesar 3,89 , sehingga $t_{\text {hitung }}>t_{\text {tabel }}$ maka Ho ditolak, artinya terdapat hubungan positif (dengan tingkat hubungan rendah) dansignifikan antara keterampilan komunikasi lisan dengan prestasi belajar kimia pada siswa kelas XI MIA Mataram dan Lombok Barat.

Hasil uji analisis statistik deskriptif digunakan nilai rata-rata (mean), dan diinterpretasikan secara deskriptif berdasarkan kategori keterampilan komunikasi lisan dan prestasi belajar kimia siswa. Berdasarkan data pada kategori hasil keterampilan komunikasi lisan dan prestasi belajar kimia siswa kelas XI MIA masing-masing SMAN di Mataram dan Lombok Barat rata-rata strata setiap sekolah dapat dilihat pada Gambar 1.

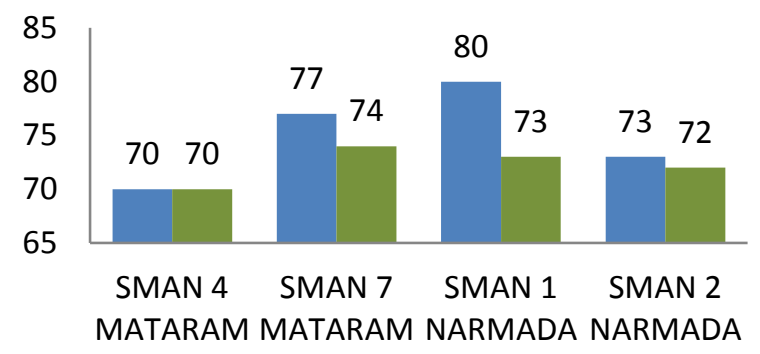

PRESTASI KOMUNIKASI LISAN

Gambar 1. Keterampilan Komunikasi Lisan dan Prestasi Belajar Kimia.

Jika dilihat dari wilayah sekolah yaitu di Mataram dan Lombok Barat, maka hasil uji analisis statistik deskriptif berdasarkan nilai rata-rata (mean), dapat dilihat pada Gambar 2.

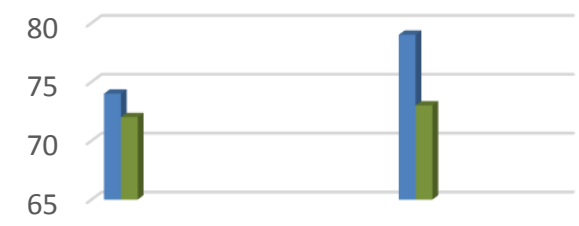

SMAN MATARAM SMAN LOMBOK BARAT

\section{PRESTASI KOMUNIKASI LISAN}

Gambar 2.Keterampilan Komunikasi Lisan dan Prestasi Belajar Kimia berdasar wilayah

Hubungan antara rata-rata hasil keterampilan komunikasi lisan dan rata-rata prestasi belajar kimia untuk setiap sekolah adalah hubungan positif atau searah. Hasil penelitian ini juga menunjukkan bahwa semakin tinggi wilayah atau tingkatan siswa, maka kemampuan keterampilan komunikasi lisan akan semakin meningkat juga. Selain itu, terdapat hubungan antara keterampilan komunikasi lisan dan prestasi belajar kimia yang dimilikinya.

Menurut Amelia (2015) bahwa jika suatu pesan tersebut sudah dimengerti maka akan memperoleh hasil yang diinginkan. Begitu sebaliknya, siswa bisa memahami suatu materi jika komunikasi berjalan dengan baik. Baik itu komunikasi dengan guru atau siswa lain. Untuk mendapatkan hasil prestasi belajar yang baik salah satu faktornya jika antara kemampuan keterampilan komunikasi lisan dengan prestasi belajar kimia dapat saling berhubungan.

Keterampilan komunikasi lisan memiliki banyak faktor. Faktor-faktor tersebut dapat dikategorikan dalam dua kelompok, yakni faktor yang menghambat dan faktor yang mendukung. Faktor yang menghambat keterampilan berkomunikasi lisan dalam proses pembelajaran yakni berupa lingkungan kelas yang kurang mendukung keaktifan siswa sebagai bentuk keterampilan berkomunikasi lisan dalam proses pembelajaran di kelas seperti guru yang tidak memberikan kesempatan untuk aktif dan kurang menghargai keterampilan siswa serta teman-teman kelas cenderung mengejek temannya yang aktif pada saat proses pembelajaran. Faktor yang mendukung tingginya komunikasi lisan siswa di kelas antara lain sikap respek guru terhadap siswa dan lingkungan kelas yang mendukung (Goss, Sonnemann, \& Griffiths, 2017). Selain itu harapan guru terhadap siswa juga memengaruhi keaktifan siswa di kelas (Papageorge \& Gershenson, 2016).

Menurut Ahmadi dan Supriyono (2011) merinci faktor yang mempengaruhi prestasi dalam belajar digolongkan secara rinci menjadi dua faktor yaitu internal dan eksternal. Pertama "faktor internal : (1). faktor jasmani (fisiologi). misalnya penglihatan, pendengaran, struktur tubuh dan sebagainnya; (2). faktor psikologi, antara lain; (a). faktor intelektif yang meliputi: faktor potensial yaitu kecerdasan, bakat dan faktor kecakapan nyata yaitu prestasi yang telah dimiliki, (b). faktor non intelektif, yaitu unsurunsur kepribadian tertentu seperti sikap, kebiasaan, minat, kebutuhan, motivasi, emosi; (3). faktor kematangan fisik maupun psikis (Ahmadi \& Supriyono, 2011). Kedua Faktor Eksternal; (1). faktor sosial yang terdiri atas; (a). lingkungan keluarga, (b). lingkungan sekolah, (c). Lingkungan masyarakat, (d). lingkungan kelompok; (2). faktor budaya seperti adat istiadat, ilmu pengetahuan, teknologi, kesenian; (3). faktor lingkungan fisik seperti fasilitas rumah, fasilitas belajar, iklim. 


\section{Chemistry Education Practice, 4 (3), 2021 - 241}

Hakim, Andayani, Siahaan

\section{SIMPULAN}

Berdasarkan hasil penelitian dan pembahasan yang telah diuraikan, maka dapat disimpulkan bahwa: (1) Terdapat hubungan yang positif dan signifikan antara keterampilan komunikasi lisan dengan prestasi belajar kimia siswa kelas XI MIA di SMAN Mataram dan Lombok Barat Tahun Ajaran 2020/2021. (2) Keterampilan komunikasi lisan dan prestasi belajar kimia siswa kelas XI MIA di SMAN Mataram dan Lombok Barat Tahun Ajaran 2020/2021, secara keseluruhan termasuk kategori tinggi.

\section{SARAN}

Dalam penelitian yang telah dilakukan diperoleh nilai koefisien kontribusi yang terbilang sangat rendah. Hal ini menunjukkan bahwa kemampuan komunikasi lisan masih banyak dipengaruhi oleh variabel-variabel lain seperti minat, lingkungan sosial, lingkungan sekolah dan sebagainya. Oleh karena itu, diharapkan dalam penelitian selanjutnya agar melakukan penelitian yang berbeda untuk mengetahui faktor-faktor lain yang mempengaruhi kemampuan keterampilan komunikasi lisan. Pembelajaran kimia di sekolah seharusnya mampu melatih keterampilan komunikasi lisan, karena keterampilan komunikasi lisan sangat diperlukan dalam kehidupan seharihari. Bagi peneliti selanjutnya dapat dipikirkan suatu metode atau model pembelajaran dalam pembelajaran kimia yang mampu melatih keterampilan komunikasi lisan kepada siswa.

\section{DAFTAR PUSTAKA}

Ahmadi, A., dan Supriyono, W. 2011. Psikologi Belajar. Jakarta: Rineka Cipta.

Amelia, Fitrah dan Maya Trismawati. 2015. Hubungan Antara Kemampuan Komunikasi Lisan Dan Kemampuan Pemahaman Matematis Terhadap Hasil Belajar Matematika Siswa Kelas VIII Di SMP Negeri 4 Batam Tahun Pelajaran 2013/2014. Jurnal PHYTAGORAS. 4(1): 10-20.

Aulia., Mia., Suwatno., Budi Santoso. 2018. Meningkatkan Keterampilan Komunikasi Lisan Melalui Metode Storytelling. Jurnal Manajerial. 3(4): 110-122.

Arikunto, S. 2013. Dasar-Dasar Evaluasi Pendidikan Edisi 2. Jakarta: Bumi.

Arikunto, S. 2016. Prosedur Penelitian Suatu Pendekatan Praktik. Jakarta: Bumi Aksara.

Fatmadewi, Vita dan Eli Rohaeti. 2019. Penerapan Model PQ4R Terintegrasi Teknik Mind Mapping terhadap Prestasi Belajar dan
Keterampilan Komunikasi. Jurnal Pendidikan Matematika Universitas Negeri Yogyakarta. 7(2): 89-99.

Goss, P., Sonnemann, J., \& Griffiths, K. 2017. Engaging Students: Creating Classrooms that Improve Learning. Victoria: Grattan Institute.

Hamdi, A.S. 2014. Metode Penelitian Kuantitatif Aplikasi dalam Pendidikan. Yogyakarta: CV Budi Utama.

Hutagalung, I. 2007. Pengembangan kepribadian (Tinjauan Praktis Menuju Pribadi Positif). Jakarta: Indeks.

Iftitahurrahimah., Yayuk Andayani., dan Syarifa Wahidah A.I. 2019. Pengaruh Model

Problem Based Learning (PBL)

Terhadap Kemampuan Komunikasi Siswa Materi Pokok Larutan Elektrolit Dan Non-Elektrolit. Jurnal Pijar MIPA. 15(1): 7-12.

Mulyasa, E. 2005. Menjadi Guru Profesional. Bandung: Remaja Rosda Karya.

Papageorge, N., \& Gershenson, S. 2016. Do Teacher Expectations Matter. The Review of Economics and Statistics. 102(2): 234-251.

Ridwan. 2005. Metode dan Teknik Penyusunan Tesis. Bandung: CV Alfa Beta.

Rubiman dan Siti Raudhatul K. 2012. Pengaruh Media Pembelajaran Terhadap Hasil Belajar Ikatan Ion. Jurnal Teknodik. 16(1): 1-8.

Sanjaya, W. 2008. Strategi Pembelajaran Beriorentasi Standar Proses Pendidikan. Jakarta: Kencana Prenada Media Group.

Sugiyono. 2016. Statistik Untuk Penelitian. Bandung: Alfabeta.

Yusefni, 2015. Analisis Hubungan Aktivitas Writing to Learn dengan kemampuan Berkomunikasi Lisan Siswa dalam Pembelajaran Science Writing Heuristic. Prosiding Simposium Nasional Inovasi dan Pembelajaran Sains. Bandung: 585-588. 